\title{
Dorsal Anterior Cingulate Function in Posttraumatic Stress Disorder
}

\author{
Lisa M. Shin \\ Department of Psychology, Tufts University, Medford, MA and Department of Psychiatry, \\ Massachusetts General Hospital
}

George Bush

Department of Psychiatry, Massachusetts General Hospital and Harvard Medical School, Boston, $M A$

Paul J. Whalen

Department of Psychology, Dartmouth College, Hanover, $\mathrm{NH}$

Kathryn Handwerger

Department of Psychology, Tufts University, Medford, $M A$

Paul A. Cannistraro

Department of Psychiatry, Massachusetts General Hospital and Harvard Medical School, Boston, $M A$

\section{Christopher I. Wright}

Department of Psychiatry, Massachusetts General Hospital and Harvard Medical School, Boston, MA and Brigham Behavioral Neurology Group, Department of Neurology,

Brigham and Women's Hospital, Boston, MA

Brian Martis

Department of Psychiatry, University of Michigan, Ann Arbor, MI

Michael L. Macklin

VA Research Service, Manchester, NH

Natasha B. Lasko and Scott P. Orr

Department of Psychiatry, Massachusetts General Hospital and Harvard Medical School,

Boston, MA and VA Research Service, Manchester, NH

Roger K. Pitman and Scott L. Rauch

Department of Psychiatry, Massachusetts General Hospital and Harvard Medical School,

Boston, $M A$

\footnotetext{
Dr. Shin received support from a NARSAD Young Investigator Award. Dr. Wright was supported by the Robert Wood Johnson Foundation and NIMH grant (MH64806). Drs. Rauch and Pitman were supported by NIMH grants MH-60219 and MH-54636, respectively. Dr. Orr received support from a Veterans Affairs Medical Research Service Merit Review grant. We would like to thank James Murrough and Rachel Karpf for their assistance with data analysis, the individuals who served as research participants, and Mary Foley and Lawrence White for their technical assistance.

Correspondence concerning this article should be addressed to: Lisa M. Shin, Department of Psychology, Tufts University, 490 Boston Avenue, Medford, MA 02155. E-mail: lisa.shin@tufts.edu.

(C) 2007 International Society for Traumatic Stress Studies. Published online in Wiley InterScience (www.interscience.wiley.com) DOI: 10.1002/jts.20231
} 
Previous neuroimaging research has shown diminished anterior cingulate cortex (ACC) function in posttraumatic stress disorder (PTSD), with most of these findings occurring in pregenuallsubgenual ACC. This study investigates whether dorsal ACC (dACC) function is also diminished in PTSD. The authors used functional magnetic resonance imaging to study $d A C C$ function during the performance of the counting Stroop. Thirteen men with PTSD and 13 trauma-exposed men without PTSD participated. In the interference-neutral comparison, both groups showed response time increases and dACC activations. These results suggest that $d A C C$ function in PTSD is not diminished during the performance of this nonemotional task. In fact, there were statistical trends in the opposite direction. These findings will help to better characterize functional brain abnormalities in this disorder.

For over a decade, researchers have used neuroimaging techniques to study brain function in posttraumatic stress disorder (PTSD). An immediate goal of this research is to determine whether brain regions or networks function abnormally in this disorder. Information about the structure or function of brain regions in PTSD could potentially inform diagnosis, the identification of risk factors, and the prediction of treatment response.

One of the most consistent functional neuroimaging findings in PTSD has been that of relatively diminished activation in the medial prefrontal cortex, including the anterior cingulate cortex (ACC) and the medial frontal gyrus. These brain regions are involved in a variety of domains, including the processing of emotional information and the retention of information about safety signals (Bush, Luu, \& Posner, 2000; Milad \& Quirk, 2002; Quirk, Russo, Barron, \& Lebron, 2000; Vogt, Finch, \& Olson, 1992). Decreased activation or failure to activate the ACC in PTSD has been demonstrated during the presentation of traumatic narratives (Bremner, Narayan et al., 1999; Britton, Phan, Taylor, Fig, \& Liberzon, 2005; Lanius et al., 2001; Lindauer et al., 2004; Shin et al., 1999), negative nontraumatic stimuli (Lanius et al., 2003; Phan, Britton, Taylor, Fig, \& Liberzon, 2006), combat pictures and/or sounds (Bremner, Staib et al., 1999; Yang, Wu, Hsu, \& Ker, 2004), and fearful facial expressions (Shin et al., 2005; Williams et al., 2006). Relatively diminished activation of the ACC in PTSD has also been shown during extinction after fear conditioning (Bremner et al., 2005), as well as during auditory continuous performance
(Semple et al., 2000), auditory oddball (Bryant et al., 2005), emotional Stroop interference (Bremner et al., 2004; Shin et al., 2001), and emotional word retrieval tasks (Bremner et al., 2003). Posttraumatic stress disorder symptom severity appears to be inversely associated with ACC activation, such that the greater the symptom severity, the lower the ACC activation (Shin et al., 2005; Williams et al., 2006).

Most of the findings of relatively diminished activation in the ACC in PTSD have occurred in pregenual or subgenual ACC (portions of the ACC that are anterior and ventral to the genu of the corpus callosum). This suggests that these subregions of the ACC may be more involved in the pathophysiology of PTSD as compared to more dorsal portions of the ACC (superior to the corpus callosum). Indeed, pregenual and subgenual ACC appear to be activated in tasks involving emotional material compared to the dorsal ACC (dACC), which is thought to be more involved in the processing of conflict, selection of responses, and detection of errors during nonemotional cognitive tasks (Bush et al., 2000). However, previous studies have not assessed dACC function in PTSD using a cognitive task designed to activate that specific subregion. In the current study, we assessed dACC function in PTSD and trauma-exposed comparison participants without PTSD using functional magnetic resonance imaging (fMRI) and a previously validated cognitive task, the counting Stroop (Bush et al., 1998).

In the counting Stroop, participants are asked to count the number of words presented on the screen and to press 


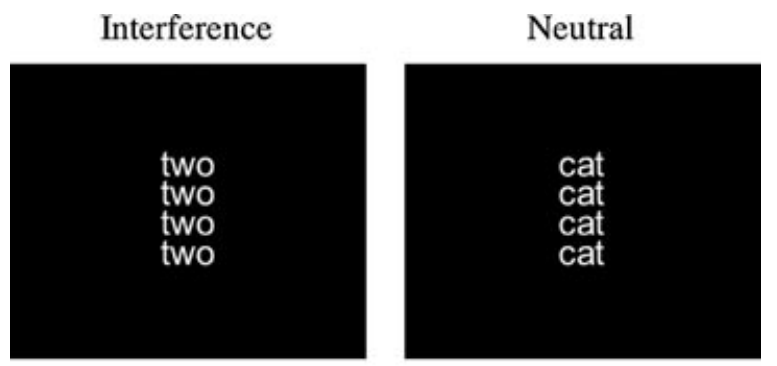

Correct Response $=4$

Figure 1. Sample stimuli from the counting Stroop.

a button corresponding to the correct number. In the interference condition, the presented words refer to numbers (e.g., "two") and the meaning of the word never matches the correct response (see Figure 1). In the neutral condition, the words are unrelated to numbers (e.g., "dog," “cat"). Comparison of the interference versus neutral conditions yields $\mathrm{fMRI}$ signal increases in $\mathrm{AACC}$ in healthy individuals (Bush et al., 1998, 1999; Matthews, Paulus, Simmons, Nelesen, \& Dimsdale, 2004). If the ACC abnormality in PTSD extends to dorsal portions of this structure, then the PTSD group ought to show decreased dACC activation and/or behavioral performance deficits during the counting Stroop. Alternatively, if the ACC abnormality is confined to more ventral regions of the ACC, then the PTSD and control groups should show similar dACC activation and behavioral performance.

Most behavioral studies involving the Stroop task and PTSD have used emotional versions of the Stroop to examine attentional biases (e.g., Bryant \& Harvey, 1995; Constans, McCloskey, Vasterling, Brailey, \& Mathews, 2004; Field et al., 2001; Foa, Feske, Murdock, Kozak, \& McCarthy, 1991; Kaspi, McNally, \& Amir, 1995; Litz et al., 1996; Thrasher, Dalgleish, \& Yule, 1994; Vrana, Roodman, \& Beckham, 1995). Fewer studies have implemented nonemotional Stroop paradigms (Bremner et al., 2004; Kanagaratnam \& Asbjornsen, in press; Litz et al., 1996; Stein, Kennedy, \& Twamley, 2002; Vasterling, Brailey, Constans, \& Sutker, 1998; Vasterling et al., 2002). Of these, only one study has reported significantly worse Stroop performance in a PTSD group compared to a trauma-exposed comparison group without PTSD (Litz et al., 1996). Thus, behavioral performance of the standard, nonemotional Stroop appears to remain intact in most samples of PTSD in the existing literature.

\section{METHOD}

\section{Participants}

Participants were 26 trauma-exposed men without a history of head injury, neurological disorders, or other major medical conditions. Thirteen participants met the Diagnostic and Statistical Manual of Mental Disorders, Fourth Edition (DSM-IV; American Psychiatric Association, 1994) diagnostic criteria for current PTSD (PTSD group) and 13 participants (who were exposed to criterion A traumatic events) never had PTSD (control group) as determined by a structured clinical interview (the ClinicianAdministered PTSD Scale [CAPS]; Weathers, Keane, \& Davidson, 2001). Participants had served in combat in Vietnam (10 PTSD, 8 control) or were firefighters (3 PTSD, 5 control). All cases of PTSD were chronic ( $>10$ years). Twenty-four participants were right-handed, and 2 (1 PTSD, 1 Control) were left-handed (Oldfield, 1971). No participant was taking psychotropic or cardiovascular medication at the time of study. These 26 individuals also participated in another previously reported study involving a separate task designed to study amygdala function (Shin et al., 2005).

The PTSD and control groups did not differ in age (PTSD $M=52.8$ years, $S D=7.3$; control $M=49.7$ years, $S D=8.9 ; F<1$ ) or marital status (PTSD $=69 \%$ married, control $=85 \%$ married; $), \chi^{2}(1, N=26)<1$. The control group had an average of 1.8 more years of education than the PTSD group (PTSD $M=13.8$ years, $S D=2.3$; control $M=15.6$ years, $S D=1.9), F(1,24)=5.02, p<.05$. Compared to the control group, the PTSD group had significantly greater PTSD symptom severity, as measured by the CAPS (PTSD $M=62.0, S D=25.2$; control $M=3.3$, $S D=6.0), F(1,22)=61.90, p<.001$. The PTSD group also had significantly higher scores on the Beck Depression Inventory (BDI; Beck \& Steer, 1987) (PTSD 
$M=20.7, \quad S D=17.0 ;$ control $M=4.2, \quad S D=4.3)$, $F(1,24)=11.52, p<.01$. Finally, the PTSD group had significantly higher scores on the Beck Anxiety Inventory (BAI; Beck \& Steer, 1990) (PTSD $M=18.8, S D=14.5$; control $M=5.0, S D=6.2), F(1,24)=10.08, p<.01$.

The Structured Clinical Interview for DSM-IV (SCID; First, Spitzer, Gibbon, \& Williams, 1995) was used to assess for other Axis I psychiatric disorders. Participants in the PTSD group met criteria for the following current comorbid diagnoses: major depression $(n=4)$, dysthymia $(n=2)$, bipolar II $(n=1)$, panic disorder $(n=3)$, social phobia $(n=2)$, and specific phobia $(n=1)$. None of the participants in either group met diagnostic criteria for current alcohol or substance use disorders. None of the participants in the control group met criteria for any current Axis I diagnosis. Past histories of alcohol dependence (which are not uncommon among Vietnam veterans) occurred in 5 PTSD and 2 control participants. Past histories of drug dependence occurred in 2 PTSD and 0 control participants.

The Partners Healthcare System (Boston, MA) and Veterans Affairs Medical Center (Manchester, NH) Institutional Review Boards approved this study. Written informed consent was obtained from each participant.

\section{Behavioral Procedures}

Task. Participants performed the counting Stroop (Bush et al., 1998) during fMRI data acquisition. On each trial, participants viewed a set of identical words (1-4 words per trial) displayed simultaneously on a screen; they were asked to count the number of words displayed and to press a button corresponding to that number. Each trial was 1.5 seconds in duration and consisted of a blank screen $(50 \mathrm{~ms})$ followed by a word set $(1.45 \mathrm{~s})$. Participants responded using a keypad consisting of four horizontally arranged buttons that represented the numbers 1, 2, 3, and 4 from left to right. Participants used the middle and index fingers of their left hand to press the 1 and 2 buttons, respectively; participants used the index and middle fingers of their right hands to press the 3 and 4 buttons, respectively. Response times and error rates were compiled on a Macintosh computer (Cupertino, CA) during task performance. Participants received 40 practice trials before fMRI scanning began.

Stimuli. Stimuli were affectively neutral words that named animals (dog, cat, mouse, bird) and words that named numbers (one, two, three, four). The animal words made up the neutral $(\mathrm{N})$ condition, in which there was no conflict between the meaning of the word and the correct response. The number words made up the interference (I) condition, in which there was always a conflict between the meaning of the word and the correct response (see Figure 1). Stimuli were presented in eight blocks (30 s each) alternating between conditions ( $\mathrm{N}$ and $\mathrm{I}$ ) per functional run. Each run began and ended with $30 \mathrm{~s}$ of a fixation baseline, which involved simply focusing on a central fixation cross (e.g., +ININININ+). Each participant completed two functional runs, and the order of conditions was counterbalanced across participants and groups. The stimuli were displayed using standardized software (MacStim 2.5.9; Darby) and a Sharp XG-2000V color LCD projector (Osaka, Japan). Immediately prior to this task, all participants had viewed blocks of neutral, happy, and fearful facial expressions in a passive viewing paradigm (Shin et al., 2005).

\section{fMAl Procedures}

Scans were obtained from a Symphony/Sonata 1.5 Tesla whole body high-speed imaging device equipped for echo planar imaging (EPI; Siemens Medical Systems, Iselin, NJ) with a 3-axis gradient head coil. Head movement was restricted using expandable foam cushions. After an automated scout image was acquired and shimming procedures were performed to optimize field homogeneity (Reese, Davis, \& Weisskoff, 1995), high-resolution threedimensional (3D) magnetization-prepared rapid acquisition gradient-echo (MP-RAGE) sequences (TR/TE/flip angle $=7.25 \mathrm{~ms} / 3 \mathrm{~ms} / 7^{\circ}$ ) with an in-plane resolution of $1.3-\mathrm{mm}$ and $1-\mathrm{mm}$ slice thickness, were collected for positioning the slice prescription of the subsequent sequences. Then, a T1-weighted (TR/TE/flip angle $=8 \mathrm{~s} / 39$ 
$\mathrm{ms} / 90^{\circ}$ ) and a T2-weighted (TR/TE/flip angle $=10 \mathrm{~s} / 48$ $\mathrm{ms} / 120^{\circ}$ ) sequence were gathered. Functional MRI (blood oxygenation level dependent (BOLD; Kwong et al., 1992) images were acquired using a gradient echo $\mathrm{T} 2 *$-weighted sequence $\left(\mathrm{TR} / \mathrm{TE} /\right.$ flip angle $\left.=2.5 \mathrm{~s} / 40 \mathrm{~ms} / 90^{\circ}\right)$. Prior to each scan, four images were acquired and discarded to allow longitudinal magnetization to reach equilibrium. The $\mathrm{T} 1, \mathrm{~T} 2$, and functional images were collected in the same plane (24 coronal slices angled perpendicular to the anterior commissure-posterior commissure [AC-PC] line) with the same slice thickness $(7 \mathrm{~mm}$, skip $1 \mathrm{~mm}$; voxel size $3.125 \times 3.125 \times 8 \mathrm{~mm}$ ), excitation order (interleaved), and phase encoding (foot-to-head).

Data Analysis. Response times from correct trials only were averaged within each condition and each run for each participant. Errors were expressed as a percentage of the total number of trials on which the participant responded within each condition and each run for each participant. Behavioral data from 1 control participant were lost due to technical difficulties.

Preprocessing and statistical analysis of the fMRI data were performed using the SPM99 software package (Wellcome Department of Cognitive Neurology, London, UK; Friston, Frith, Liddle, \& Frackowiak, 1991). Within SPM99, images were motion corrected (sinc interpolation) and transformed into a standard (Montreal Neurological Institute; MNI) stereotactic space (bilinear interpolation). Images were then smoothed with a 6-mm Gaussian kernel.

In SPM99, voxelwise interference vs. neutral contrast images were created for each participant. Data from both runs per participant were included in this analysis. At each voxel, the data were fit to a linear statistical model by the method of least squares. The design was modeled using a boxcar function convolved with the hemodynamic response function. Hypotheses were tested as contrasts in which linear compounds of the model parameters were evaluated using $t$ statistics, which were then transformed to $z$-scores. Random effects analyses were then performed to assess (a) the difference between conditions within each group, and (b) the difference between groups on the difference between conditions (i.e., Group $\times$ Condition interaction).

The statistical parametric maps resulting from the random effects analyses were inspected for activations in the dACC, our a priori region of interest. The dACC was defined as the portion of the AC superior to the corpus callosum, between $y=0$ and $y=+30 \mathrm{~mm}$ (Bush et al., 2002). For the dACC, we used a significance threshold of $p<.05$ (two-tailed), corrected for multiple comparisons (based on the $10 \mathrm{~mL}$ volume of dACC, (Rauch et al., 2003). For regions about which we had no a priori prediction, we used a more conservative constant significance threshold of $p<.00005$, uncorrected $(z \geq 3.90)$.

To determine whether PTSD symptoms were related to dACC activation, we ran correlational analyses between CAPS scores and extracted values from dACC in each group (shown in Figure 2). Our significance threshold for this analysis was $p<.05$, two-tailed.

To determine whether dACC gray matter densities differed between groups, we conducted a post hoc voxelbased morphometric analysis. We spatially normalized, segmented, and smoothed (12-mm full width at half maximum [FWHM]) 3D MPRAGE images within SPM99 according to previously published methods (Ashburner \& Friston, 2000). The resulting images were compared between groups in a voxelwise manner in accordance with the general linear model (Ashburner \& Friston, 2000). The smoothing kernel of $12 \mathrm{~mm}$ was chosen to facilitate comparison with previous voxel-based morphometric studies of PTSD (Corbo, Clement, Armony, Pruessner, \& Brunet, 2005; Yamasue et al., 2003). Due to missing data in 3 control participants, this analysis was conducted with 9 control and 10 PTSD participants. We focused this analysis on only the dACC and used a significance threshold of $p<.05$ (two-tailed), corrected for multiple comparisons.

\section{RESULTS}

\section{Behavioral Results}

Three participants with PTSD and 1 control participant had unusually high error rates $(20-44 \%)$ in the 

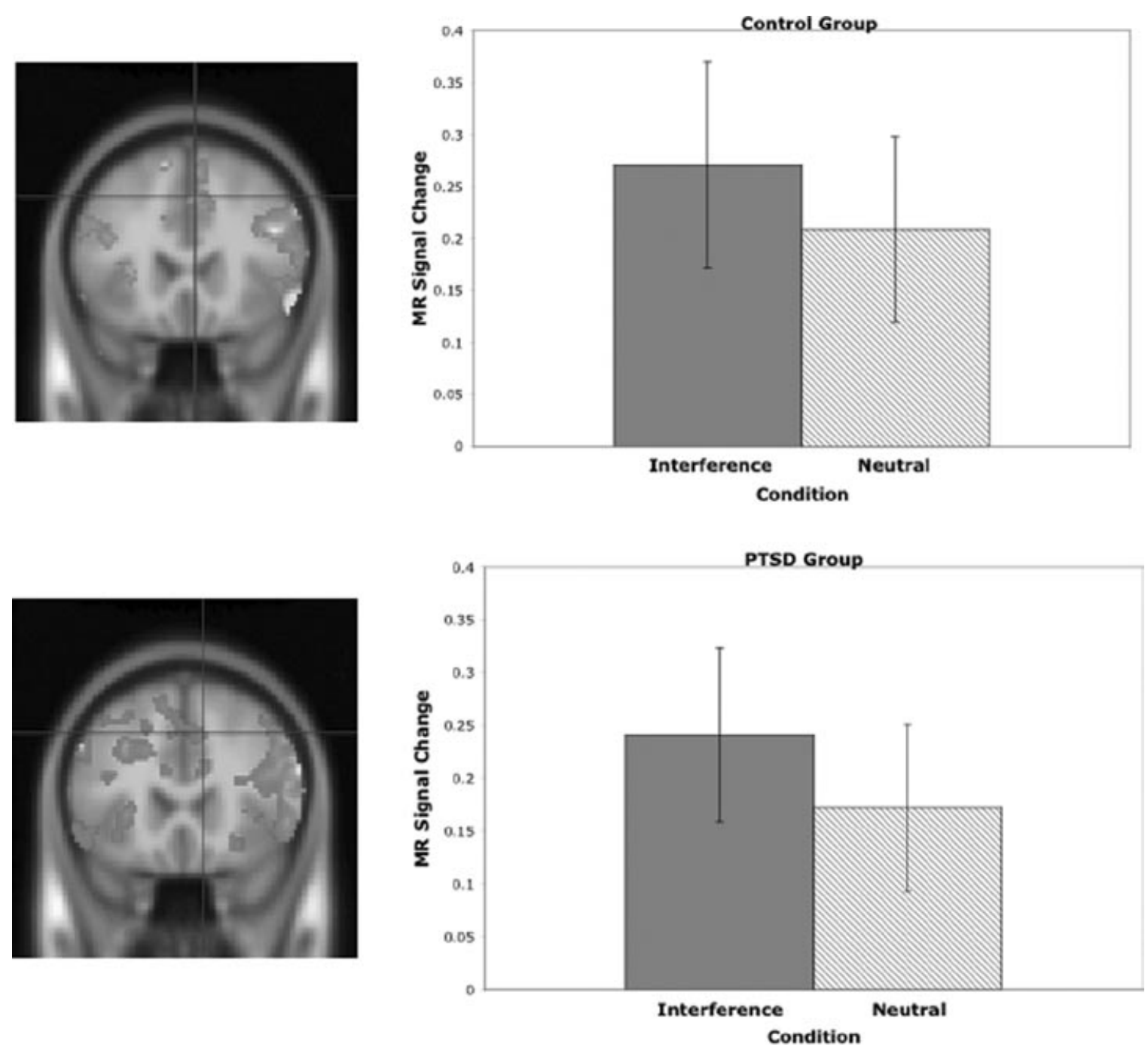

Figure 2. The functional images show activation in dorsal anterior cingulate cortex (dACC) in the interference versus neutral contrast separately in the control $(n=12$; top) and PTSD $(n=10$; bottom) groups. Functional data are superimposed on a standard SPM99 T1 template, displayed according to neurological convention. The bar graph shows magnetic resonance (MR) signal change in the dACC (PTSD: $\mathrm{MNI}=+10,+22,+42$; control: $\mathrm{MNI}=+4,+22,+42$ ) in each condition (relative to fixation baseline) for each group. $\mathrm{MNI}=$ Montreal Neurological Institute.

interference condition, averaged across both runs. Because this is not an event-related study, we were unable to remove fMRI datapoints corresponding to the trials on which errors were made. Given that high error rates may indicate a failure to comprehend or attend to the task (which could render the corresponding fMRI data uninterpretable) and the substantial evidence showing that committing errors activates the anterior cingulate cortex (Bush et al., 2000;
Critchley, Tang, Glaser, Butterworth, \& Dolan, 2005; Holroyd et al., 2004; Mathalon, Whitfield, \& Ford, 2003), behavioral and AMRI BOLD data from these four participants were deemed (a priori) unreliable and removed from all analyses (Bush et al., 1998, 1999). Removing data from these four participants did not alter the pattern of behavioral and fMRI findings, with one exception as noted below. 
Response times and error rates were submitted to separate 2 (Diagnosis: PTSD, control) $\times 2$ (Condition: interference, neutral) ANOVAs. As expected, a significant main effect of condition indicated that response times were greater in the interference condition compared to the neutral condition, $F(1,19)=66.30, p<.001$ (see Table 1 ). The main effect of group, $F<1$, and interaction between condition and group, $F(1,19)=3.13$, ns), were not significant.

With regard to error rates, the main effect of condition was significant, $F(1,19)=15.45, p<.001$; error rates were higher in the interference condition than in the neutral condition (see Table 1). The main effect of group, $F<1$, and interaction between condition and group, $F<1$, were not significant.

\section{fMRI Results}

In the control group $(n=12)$, BOLD signal increases occurred in dACC. In the PTSD group $(n=10)$, BOLD signal increases were found in AACC, as well as in regions about which we had no a priori hypothesis (see Table 2).

In the control group, BOLD signal decreases occurred in subgenual ACC. The PTSD group exhibited BOLD signal decreases in bilateral insula, with a trend for a decrease in subgenual ACC.

The voxelwise Condition $\times$ Diagnosis interaction revealed no significant group differences. Furthermore, BOLD signal increases in the $\mathrm{dACC}$ regions shown in Figure 2 did not significantly differ between groups

Table 1. Response Times and Error Rates in Posttraumatic Stress Disorder (PTSD) and Control Groups

\begin{tabular}{|c|c|c|c|c|}
\hline & \multicolumn{2}{|c|}{$M$} & \multicolumn{2}{|c|}{$S D$} \\
\hline & PTSD & Control & PTSD & Control \\
\hline \multicolumn{5}{|c|}{ Response time in $\mathrm{ms}$} \\
\hline Interference & 821 & 830 & 107 & 92 \\
\hline Neutral & 772 & 754 & 105 & 69 \\
\hline \multicolumn{5}{|c|}{ Error rate } \\
\hline Interference & $4.2 \%$ & $4.0 \%$ & $2.7 \%$ & $1.6 \%$ \\
\hline Neutral & $2.5 \%$ & $1.8 \%$ & $1.1 \%$ & $1.2 \%$ \\
\hline
\end{tabular}

Note. $\mathrm{ms}=$ milliseconds.
( $p=.85$; effect size $r=.04$ ). In a different location within the dACC, a trend for greater BOLD signal increases in the PTSD versus control group occurred in two separate foci: (a) $\mathrm{MNI}=+12,+8,+48, z=2.02, p<.06$, effect size $r=.29$; and (b) $\mathrm{MNI}=-6,+8,+32, z=1.92$, $p<.08$, effect size $r=.43$. However, these activations did not exceed our significance threshold and their spatial extent was relatively small (7 and 8 voxels, respectively). When the data from the 4 participants with high error rates were added back into the analysis, the $p$-values associated with these two small activations decreased to $p<.02$ and $p<.07$, respectively. This is not surprising given that these participants made a large percentage of errors, which is known to activate dACC.

Activation of $\mathrm{dACC}$ in the interference versus neutral comparison was not significantly correlated with CAPS total scores or with scores on subscales of the CAPS in either group.

The post hoc voxel-based morphometric analysis yielded no significant between-group differences in gray matter density in dACC.

\section{DISCUSSION}

In the current study, we found no evidence of diminished function in the dACC in PTSD during the affectively neutral counting Stroop task. If anything, the PTSD group tended to show greater activation than the control group in a small area of dACC, although that finding did not meet our a priori criteria for significance. Dorsal ACC activation was not significantly related to symptom severity, and the groups did not differ in terms of gray matter densities, as determined by voxel-based morphometry.

These results are broadly consistent with the hypothesis that diminished ACC function may be more confined to pregenual and subgenual ACC. Interestingly, this same PTSD group (who showed intact dACC function here) also showed diminished pregenual ACC function during the passive viewing of emotional facial expressions (Shin et al., 2005). Furthermore, in that study, pregenual ACC function was inversely related to PTSD symptom severity. The current results are also convergent with those of 
Table 2. Interference Versus Neutral Comparison in Posttraumatic Stress Disorder (PTSD) and Control Groups

\begin{tabular}{|c|c|c|c|c|c|}
\hline Region & $\begin{array}{c}\text { PTSD } \\
Z\end{array}$ & $\begin{array}{c}\text { MNI Coordinates } \\
\quad(x, y, z)\end{array}$ & Region & $\begin{array}{c}\text { Control } \\
Z\end{array}$ & $\begin{array}{c}\text { MNI Coordinates } \\
\quad(x, y, z)\end{array}$ \\
\hline \multicolumn{6}{|c|}{ BOLD Signal increases } \\
\hline \multirow[t]{3}{*}{ Dorsal ACC } & 2.59 & $+10,+22,+42$ & Dorsal ACC & 2.59 & $+4,+22,+42$ \\
\hline & 2.75 & $-8,+28,+40$ & & & \\
\hline & 2.83 & $0,+14,+50$ & & & \\
\hline Brainstem & 4.44 & $+4,-22,-26$ & & & \\
\hline R Inferior temporal gyrus & 4.40 & $+58,-46,-16$ & & & \\
\hline \multirow[t]{2}{*}{ L Occipital cortex } & 4.38 & $-28,-88,+36$ & & & \\
\hline & 3.91 & $-32,-94,+12$ & & & \\
\hline \multirow[t]{2}{*}{ R Precentral gyrus } & 3.98 & $+36,-16,+60$ & & & \\
\hline & & BOLD Signal d & & & \\
\hline \multirow[t]{3}{*}{ Subgenual ACC } & $3.17(n s)$ & $-6,+18,-12$ & Subgenual ACC & 4.01 & $+6,+26,-8$ \\
\hline & $3.29(n s)$ & $-12,+20,-14$ & & & \\
\hline & 4.41 & $+38,-20,+18$ & & & \\
\hline B Insula & 4.10 & $-48,-4,-2$ & & & \\
\hline
\end{tabular}

Note. $\mathrm{BOLD}=$ blood oxygenation level dependent; $\mathrm{MNI}=$ Montreal Neurological Institute; $\mathrm{B}=$ bilateral; $\mathrm{R}=$ right; $\mathrm{L}=$ left; $\mathrm{ACC}=$ anterior cingulate cortex; ns $=$ nonsignificant.

Bremner et al. (2004), who found no group differences in ACC activation during performance of a standard, affectively neutral color Stroop. Indeed diminished ACC function may be more evident in the context of tasks involving emotional versus neutral stimuli (Bryant et al., 2005; Shin et al., 2001).

The counting Stroop has been shown to be sensitive enough to detect diminished dACC function in patient groups, such as in attention deficit/hyperactivity disorder (Bush et al., 1999). In addition, using the emotional counting Stroop, which is identical to the counting Stroop in all respects except for the stimuli used, we observed diminished function in more pregenual portions of the ACC in PTSD (Shin et al., 2001). Thus, our finding that dACC function was not diminished in PTSD cannot be explained by the use of an insensitive cognitive probe.

Our finding of no significant group difference in gray matter densities in $\mathrm{AACC}$ is consistent with our previous report of normal dACC volumes in PTSD (Rauch et al., 2003). In contrast, other previous studies have reported diminished volumes in or including dACC in PTSD (Kitayama, Quinn, \& Bremner, 2006; Woodward et al., 2006; Yamasue et al., 2003). Our relatively small study may have lacked the power to show significant between- group differences in the voxel-based morphometric analysis, although the number of participants in the current study did not differ greatly from that of Kitayama et al. (2006). An account for the inconsistency between studies remains unclear. The finding that voxel-based morphometric results may indicate group differences in shape rather than volume (Corbo et al., 2005) would seem to call for the use of more standard volumetric segmentation procedures in future studies.

The trend for greater dACC activation in PTSD was unexpected. This finding could reflect increased effort in the interference versus neutral conditions in the PTSD group. We also considered the possibility that this trend could reflect regulation of autonomic arousal during the cognitive task (Critchley et al., 2003, 2005). However, three recent studies have demonstrated that heart rate changes during the performance of Stroop tasks are not significantly higher in PTSD compared to control groups (Bremner et al., 2004; Klumpers et al., 2004; Litz et al., 1996). Other previous research shows that individuals with PTSD are not more physiologically responsive to trauma-unrelated cognitive stressors (e.g., mental arithmetic tasks) than traumaexposed individuals without PTSD (Blanchard, Kolb, Gerardi, Ryan, \& Pallmeyer, 1986; Keane et al., 1998; Orr, 
Meyerhoff, Edwards, \& Pitman, 1998) and PTSD symptom severity appears to be negatively correlated with skin conductance during a cognitive stressor (McDonagh-Coyle et al., 2001). Future fMRI studies in which psychophysiologic data are collected would be helpful in addressing these issues. If replicated in a larger sample, increased dACC activation in PTSD could indicate a functional abnormality, although it would be in the opposite direction as the functional abnormality in the pregenual and subgenual ACC.

Limitations of this study include the relatively small number of participants per group, although such sample sizes are not uncommon in functional neuroimaging research. Interpretation of any study reporting negative findings may be challenging; however, the absence of any mean differences between groups (and indeed the trend toward greater activation in PTSD in two small portions of dACC) suggests that $\mathrm{dACC}$ function appears not to be diminished in PTSD, at least in the context of this well-validated cognitive interference task. In addition, these participants participated in only the version of this task that was designed to activate the dACC. To make definitive statements concerning the relative involvement of $\mathrm{dACC}$ versus pregenual and subgenual ACC in PTSD, it would be necessary to administer separate cognitive and emotional versions of the counting Stroop in the same group of participants. As mentioned above, although these PTSD participants did not also complete the emotional counting Stroop, they did show diminished pregenual ACC function during the passive viewing of fearful facial expressions (Shin et al., 2005). Finally, future studies might implement a similar cognitive interference task using an event-related design, which would permit a more detailed analysis of error-related ACC activation.

The current findings suggest that diminished function may be more confined to pregenual and subgenual portions of the ACC in PTSD. If future studies confirm that diminished pregenual/subgenual ACC function is an adequately sensitive and specific measure, then this type of information could assist in the diagnosis of PTSD. In addition, the current and previous findings suggest that the ACC, as well as the amygdala and hippocampus, may be regions to consider in the search for neuroanatomical risk factors for the development of PTSD. Lastly, ACC function could be measured before and after treatment to determine whether functional abnormalities normalize following successful treatment (Fernandez et al., 2001; Seedat et al., 2004), and whether pretreatment activation in the ACC predicts treatment response.

\section{REFERENCES}

American Psychiatric Association. (1994). Diagnostic and statistical manual of mental disorders (4th ed.). Washington, DC: Author.

Ashburner, J., \& Friston, K. J. (2000). Voxel-based morphometryThe methods. Neuroimage, 11, 805-821.

Beck, A. T., \& Steer, R. A. (1987). Manual for the revised Beck Depression Inventory. San Antonio, TX: The Psychological Corporation.

Beck, A. T., \& Steer, R. A. (1990). Beck Anxiety Inventory Manual. San Antonio, TX: The Psychological Corporation.

Blanchard, E. B., Kolb, L. C., Gerardi, R. J., Ryan, P., \& Pallmeyer, T. P. (1986). Cardiac response to relevant stimuli as an adjunctive tool for diagnosing posttraumatic stress disorder in Vietnam veterans. Behavior Therapy, 17, 592-606.

Bremner, J. D., Narayan, M., Staib, L. H., Southwick, S. M., McGlashan, T., \& Charney, D. S. (1999). Neural correlates of memories of childhood sexual abuse in women with and without posttraumatic stress disorder. American Journal of Psychiatry, 156, 1787-1795.

Bremner, J. D., Staib, L. H., Kaloupek, D., Southwick, S. M., Soufer, R., \& Charney, D. S. (1999). Neural correlates of exposure to traumatic pictures and sound in Vietnam combat veterans with and without posttraumatic stress disorder: A positron emission tomography study. Biological Psychiatry, 45, 806-816.

Bremner, J. D., Vermetten, E., Schmahl, C., Vaccarino, V., Vythilingam, M., Afzal, N., et al. (2005). Positron emission tomographic imaging of neural correlates of a fear acquisition and extinction paradigm in women with childhood sexual-abuserelated posttraumatic stress disorder. Psychological Medicine, 35 , 791-806.

Bremner, J. D., Vermetten, E., Vythilingam, M., Afzal, N., Schmahl, C., Elzinga, B., et al. (2004). Neural correlates of the classic color and emotional Stroop in women with abuse-related posttraumatic stress disorder. Biological Psychiatry, 55, 612-620.

Bremner, J. D., Vythilingam, M., Vermetten, E., Southwick, S. M., McGlashan, T., Staib, L. H., et al. (2003). Neural correlates of declarative memory for emotionally valenced words in women 
with posttraumatic stress disorder related to early childhood sexual abuse. Biological Psychiatry, 53, 879-889.

Britton, J. C., Phan, K. L., Taylor, S. F., Fig, L. M., \& Liberzon, I. (2005). Corticolimbic blood flow in posttraumatic stress disorder during script-driven imagery. Biological Psychiatry, 57, 832840 .

Bryant, R. A., Felmingham, K. L., Kemp, A. H., Barton, M., Peduto, A. S., Rennie, C., et al. (2005). Neural networks of information processing in posttraumatic stress disorder: A functional magnetic resonance imaging study. Biological Psychiatry, 58, 111-118.

Bryant, R. A., \& Harvey, A. G. (1995). Processing threatening information in posttraumatic stress disorder. Journal of Abnormal Psychology, 104, 537-541.

Bush, G., Frazier, J. A., Rauch, S. L., Seidman, L. J., Whalen, P. J., Jenike, M. A., et al. (1999). Anterior cingulate cortex dysfunction in attention-deficit/hyperactivity disorder revealed by fMRI and the Counting Stroop. Biological Psychiatry, 45, 1542-1552.

Bush, G., Luu, P., \& Posner, M. I. (2000). Cognitive and emotional influence in anterior cingulate cortex. Trends in Cognitive Sciences, 4, 215-222.

Bush, G., Vogt, B. A., Holmes, J., Dale, A. M., Greve, D., Jenike, M. A., et al. (2002). Dorsal anterior cingulate cortex: A role in reward-based decision making. Proceedings of the National Academy of Sciences of the United States of America, 99, 523528.

Bush, G., Whalen, P. J., Rosen, B. R., Jenike, M. A., McInerney, S. C., \& Rauch, S. L. (1998). The counting Stroop: An interference task specialized for functional neuroimaging - Validation study with functional MRI. Human Brain Mapping, 6, 270-282.

Constans, J. I., McCloskey, M. S., Vasterling, J. J., Brailey, K., \& Mathews, A. (2004). Suppression of attentional bias in PTSD. Journal of Abnormal Psychology, 113, 315-323.

Corbo, V., Clement, M. H., Armony, J. L., Pruessner, J. C., \& Brunet, A. (2005). Size versus shape differences: contrasting voxel-based and volumetric analyses of the anterior cingulate cortex in individuals with acute posttraumatic stress disorder. Biological Psychiatry, 58, 119-124.

Critchley, H. D., Mathias, C. J., Josephs, O., O’Doherty, J., Zanini, S., Dewar, B. K., et al. (2003). Human cingulate cortex and autonomic control: converging neuroimaging and clinical evidence. Brain, 126, 2139-2152.

Critchley, H. D., Tang, J., Glaser, D., Butterworth, B., \& Dolan, R. J. (2005). Anterior cingulate activity during error and autonomic response. Neuroimage, 27, 885-895.

Darby, D. MacStim 2.5.9 [Computer Software]. West Melbourne, Australia: White Ant Occasional Publishing.
Fernandez, M., Pissiota, A., Frans, O., von Knorring, L., Fischer, H., $\&$ Fredrikson, M. (2001). Brain function in a patient with torture related post-traumatic stress disorder before and after fluoxetine treatment: A positron emission tomography provocation study. Neuroscience Letters, 297, 101-104.

Field, N. P., Classen, C., Butler, L. D., Koopman, C., Zarcone, J., \& Spiegel, D. (2001). Revictimization and information processing in women survivors of childhood sexual abuse. Journal of Anxiety Disorders, 15, 459-469.

First, M., Spitzer, R., Gibbon, M., \& Williams, J. (1995). Structured Clinical Interview for DSM-IV. New York: New York State Psychiatric Institute, Biometrics Research Department.

Foa, E. B., Feske, U., Murdock, T. B., Kozak, M. J., \& McCarthy, P. R. (1991). Processing of threat-related information in rape victims. Journal of Abnormal Psychology, 100, 156162.

Friston, K. J., Frith, C. D., Liddle, P. F., \& Frackowiak, R. S. (1991). Comparing functional (PET) images: The assessment of significant change. Journal of Cerebral Blood Flow and Metabolism, $11,690-699$.

Holroyd, C. B., Nieuwenhuis, S., Yeung, N., Nystrom, L., Mars, R. B., Coles, M. G., et al. (2004). Dorsal anterior cingulate cortex shows $\mathrm{fMRI}$ response to internal and external error signals. Nature Neuroscience, 7, 497-498.

Kanagaratnam, P., \& Asbjornsen, A. E. (2007). Executive deficits in chronic PTSD related to political violence. Journal of Anxiety Disorders, 21, 510-525.

Kaspi, S. P., McNally, R. J., \& Amir, N. (1995). Cognitive processing of emotional information in posttraumatic stress disorder. Cognitive Therapy and Research, 19, 433-444.

Keane, T. M., Kolb, L. C., Kaloupek, D. G., Orr, S. P., Blanchard, E. B., Thomas, R. G., et al. (1998). Utility of psychophysiological measurement in the diagnosis of posttraumatic stress disorder: Results from a Department of Veterans Affairs Cooperative Study. Journal of Consulting and Clinical Psychology, 66, 914923.

Kitayama, N., Quinn, S., \& Bremner, J. D. (2006). Smaller volume of anterior cingulate cortex in abuse-related posttraumatic stress disorder. Journal of Affective Disorders, 90, 171-174.

Klumpers, U. M., Tulen, J. H., Timmerman, L., Fekkes, D., Loonen, A. J., \& Boomsma, F. (2004). Responsivity to stress in chronic posttraumatic stress disorder due to childhood sexual abuse. Psychological Reports, 94, 408-410.

Kwong, K. K., Belliveau, J. W., Chesler, D. A., Goldberg, I. E., Weisskoff, R. M., Poncelet, B. P., et al. (1992). Dynamic magnetic resonance imaging of human brain activity during primary 
sensory stimulation. Proceedings of the National Academy of Sciences of the United States of America, 89, 5675-5679.

Lanius, R. A., Williamson, P. C., Densmore, M., Boksman, K., Gupta, M. A., Neufeld, R. W., et al. (2001). Neural correlates of traumatic memories in posttraumatic stress disorder: a functional MRI investigation. American Journal of Psychiatry, 158, 19201922.

Lanius, R. A., Williamson, P. C., Hopper, J., Densmore, M., Boksman, K., Gupta, M. A., et al. (2003). Recall of emotional states in posttraumatic stress disorder: An $\mathrm{fMRI}$ investigation. Biological Psychiatry, 53, 204-210.

Lindauer, R. J., Booij, J., Habraken, J. B., Uylings, H. B., Olff, M., Carlier, I. V., et al. (2004). Cerebral blood flow changes during script-driven imagery in police officers with posttraumatic stress disorder. Biological Psychiatry, 56, 853-861.

Litz, B. T., Weathers, F. W., Monaco, V., Herman, D. S., Wulfsohn, M., Marx, B., et al. (1996). Attention, arousal, and memory in posttraumatic stress disorder. Journal of Traumatic Stress, 9, 497-519.

Mathalon, D. H., Whitfield, S. L., \& Ford, J. M. (2003). Anatomy of an error: ERP and fMRI. Biological Psychology, 64, 119-141.

Matthews, S. C., Paulus, M. P., Simmons, A. N., Nelesen, R. A., \& Dimsdale, J. E. (2004). Functional subdivisions within anterior cingulate cortex and their relationship to autonomic nervous system function. Neuroimage, 22, 1151-1156.

McDonagh-Coyle, A., McHugo, G. J., Friedman, M. J., Schnurr, P. P., Zayfert, C., \& Descamps, M. (2001). Psychophysiological reactivity in female sexual abuse survivors. Journal of Traumatic Stress, 14, 667-683.

Milad, M. R., \& Quirk, G. J. (2002). Neurons in medial prefrontal cortex signal memory for fear extinction. Nature, 420, 7074.

Oldfield, R. C. (1971). The assessment and analysis of handedness: The Edinburgh inventory. Neuropsychologia, 9, 97-113.

Orr, S. P., Meyerhoff, J. L., Edwards, J. V., \& Pitman, R. K. (1998). Heart rate and blood pressure resting levels and responses to generic stressors in Vietnam veterans with posttraumatic stress disorder. Journal of Traumatic Stress, 11, 155-164.

Phan, K. L., Britton, J. C., Taylor, S. F., Fig, L. M., \& Liberzon, I. (2006). Corticolimbic blood flow during nontraumatic emotional processing in posttraumatic stress disorder. Archives of General Psychiatry, 63, 184-192.

Quirk, G. J., Russo, G. K., Barron, J. L., \& Lebron, K. (2000). The role of ventromedial prefrontal cortex in the recovery of extinguished fear. J Neuroscience, 20, 6225-6231.
Rauch, S. L., Shin, L. M., Segal, E., Pitman, R. K., Carson, M. A., McMullin, K., et al. (2003). Selectively reduced regional cortical volumes in post-traumatic stress disorder. Neuroreport, 14, 913916.

Reese, T. G., Davis, T. L., \& Weisskoff, R. M. (1995). Automated shimming at $1.5 \mathrm{~T}$ using echo-planar image frequency maps. Journal of Magnetic Resonance Imaging, 5, 739-745.

Seedat, S., Warwick, J., van Heerden, B., Hugo, C., Zungu-Dirwayi, N., Van Kradenburg, J., et al. (2004). Single photon emission computed tomography in posttraumatic stress disorder before and after treatment with a selective serotonin reuptake inhibitor. Journal of Affective Disorders, 80, 45-53.

Semple, W. E., Goyer, P. F., McCormick, R., Donovan, B., Muzic, R. F., Jr., Rugle, L., et al. (2000). Higher brain blood flow at amygdala and lower frontal cortex blood flow in PTSD patients with comorbid cocaine and alcohol abuse compared with normals. Psychiatry, 63, 65-74.

Shin, L. M., McNally, R. J., Kosslyn, S. M., Thompson, W. L., Rauch, S. L., Alpert, N. M., et al. (1999). Regional cerebral blood flow during script-driven imagery in childhood sexual abuse-related PTSD: A PET investigation. American Journal of Psychiatry, 156, 575-584.

Shin, L. M., Whalen, P. J., Pitman, R. K., Bush, G., Macklin, M. L., Lasko, N. B., et al. (2001). An fMRI study of anterior cingulate function in posttraumatic stress disorder. Biological Psychiatry, 50, 932-942.

Shin, L. M., Wright, C. I., Cannistraro, P. A., Wedig, M. M., McMullin, K., Martis, B., et al. (2005). A functional magnetic resonance imaging study of amygdala and medial prefrontal cortex responses to overtly presented fearful faces in posttraumatic stress disorder. Archives of General Psychiatry, 62, 273-281.

Stein, M. B., Kennedy, C. M., \& Twamley, E. W. (2002). Neuropsychological function in female victims of intimate partner violence with and without posttraumatic stress disorder. Biological Psychiatry, 52, 1079-1088.

Thrasher, S. M., Dalgleish, T., \& Yule, W. (1994). Information processing in posttraumatic stress disorder. Behaviour Research and Therapy, 32, 247-254.

Vasterling, J. J., Brailey, K., Constans, J. I., \& Sutker, P. B. (1998). Attention and memory dysfunction in posttraumatic stress disorder. Neuropsychology, 12, 125-133.

Vasterling, J. J., Duke, L. M., Brailey, K., Constans, J. I., Allain, A. N., Jr., \& Sutker, P. B. (2002). Attention, learning, and memory performances and intellectual resources in Vietnam veterans: PTSD and no disorder comparisons. Neuropsychology, 16, 514. 
Vogt, B. A., Finch, D. M., \& Olson, C. R. (1992). Functional heterogeneity in cingulate cortex: The anterior executive and posterior evaluative regions. Cerebral Cortex, 2, 435-443.

Vrana, S. R., Roodman, A., \& Beckham, J. C. (1995). Selective processing of trauma-relevant words in posttraumatic stress disorder. Journal of Anxiety Disorders, 9, 515-530.

Weathers, F. W., Keane, T. M., \& Davidson, J. R. (2001). Clinicianadministered PTSD scale: A review of the first ten years of research. Depression and Anxiety, 13, 132-156.

Williams, L. M., Kemp, A. H., Felmingham, K., Barton, M., Olivieri, G., Peduto, A., et al. (2006). Trauma modulates amygdala and medial prefrontal responses to consciously attended fear. Neuroimage, 29, 347-357.
Woodward, S. H., Kaloupek, D. G., Streeter, C. C., Martinez, C., Schaer, M., \& Eliez, S. (2006). Decreased anterior cingulate volume in combat-related PTSD. Biological Psychiatry, 59, 582587.

Yamasue, H., Kasai, K., Iwanami, A., Ohtani, T., Yamada, H., Abe, O., et al. (2003). Voxel-based analysis of MRI reveals anterior cingulate gray-matter volume reduction in posttraumatic stress disorder due to terrorism. Proceedings of the National Academy of Sciences of the United States of America, 100, 9039-9043.

Yang, P., Wu, M. T., Hsu, C. C., \& Ker, J. H. (2004). Evidence of early neurobiological alternations in adolescents with posttraumatic stress disorder: A functional MRI study. Neuroscience Letters, 370, 13-18. 